\title{
Interactions between White Matter Asymmetry and Language during Neurodevelopment
}

\author{
Jonathan 0’Muircheartaigh, ${ }^{1,2}$ Douglas C. Dean III, ${ }^{1}$ Holly Dirks, ${ }^{1}$ Nicole Waskiewicz, ${ }^{1}$ Katie Lehman, ${ }^{1}$ Beth A. Jerskey, ${ }^{3}$ \\ and Sean C.L. Deoni ${ }^{1}$ \\ ${ }^{1}$ Advanced Baby Imaging Laboratory, School of Engineering, Brown University, Providence, Rhode Island 02912, ${ }^{2}$ Department of Neuroimaging, King's \\ College London, Institute of Psychiatry, London WC2R 2 LS, United Kingdom, and ${ }^{3}$ Alpert Medical School of Brown University, Providence, Rhode Island \\ 02912
}

The human brain is asymmetric in gross structure as well as functional organization. However, the developmental basis and trajectory of this asymmetry is unclear, and its relationship(s) to functional and cognitive development, especially language, remain to be fully elucidated. During infancy and early childhood, in concert with cortical gray matter growth, underlying axonal bundles become progressively myelinated. This myelination is critical for efficient and coherent interneuronal communication and, as revealed in animal studies, the degree of myelination changes in response to environment and neuronal activity. Using a novel quantitative magnetic resonance imaging method to investigate myelin content in vivo in human infants and young children, we investigated gross asymmetry of myelin in a large cohort of 108 typically developing children between 1 and 6 years of age, hypothesizing that asymmetry would predict language abilities in this cohort. While asymmetry of myelin content was evident in multiple cortical and subcortical regions, language ability was predicted only by leftward asymmetry of caudate and frontal cortex myelin content and rightward asymmetry in the extreme capsule. Importantly, the influence of this asymmetry was found to change with age, suggesting an age-specific influence of structure and myelin on language function. The relationship between language ability and asymmetry of myelin stabilized at $\sim 4$ years, indicating anatomical evidence for a critical time during development before which environmental influence on cognition may be greatest.

\section{Introduction}

Asymmetry of cortical size and function is a well established hallmark of human neuroanatomy and neuropsychology (Bradshaw, 1978; Gannon et al., 1998; Toga and Thompson, 2003). Asymmetry of cortical volume appears phylogenetically conserved and is strongly heritable, particularly in brain regions underlying language (Thompson et al., 2001; Toga and Thompson, 2003). The asymmetric functional brain representation of language overlaps with regions of strong cerebral left-sided lateralization of volume in Broca's area (Keller et al., 2009) and the planum temporale (Shapleske et al., 1999; Hill et al., 2010). During prenatal development, however, structural asymmetries are more evident on the right side, with earlier gyrification of the superior frontal gyrus, Heschl's gyrus, and the superior temporal gyrus (DehaeneLambertz et al., 2006). At term, volumetric asymmetry is reversed compared with adults (Gilmore et al., 2007). However, the mechanisms and trajectory by which regional asymmetry changes, and

Received April 5, 2013; revised July 22, 2013; accepted Sept. 4, 2013.

Author contributions: J.O. and S.C.L.D. designed research; J.O., D.C.D., H.D., N.W., K.L., B.A.J., and S.C.L.D. performed research; J.O. and D.C.D. analyzed data; J.O., D.C.D., and S.C.L.D. wrote the paper.

This work was supported by the National Institutes of Mental Health (R01 MH087510). J.0. is supported by a Sir Henry Wellcome Postdoctoral Fellowship awarded by the Wellcome Trust (№ 096195). We thank all the families who donated their time to take part in this research.

Correspondence should be addressed to Jonathan 0'Muircheartaigh, Advanced Baby Imaging Lab, 184 Hope Street, Box D, Providence, RI 02912. E-mail: Jonathan0M@kcl.ac.uk.

DOI:10.1523/JNEUROSCI.1463-13.2013

Copyright $\odot 2013$ the authors $\quad 0270-6474 / 13 / 3316170-08 \$ 15.00 / 0$ how this relates to cognition and language development, is unclear.

Part of this explanation may come from white matter. Anatomical connections within, and between, cortical and subcortical structures partly define neural structures functionally (Passingham et al., 2002). The establishment and consolidation of this structural architecture foreshadows functional and cognitive development (Casey et al., 2005). Throughout postnatal development, neural axons become encased in a fatty myelin sheath allowing rapid and coordinated interneuronal communication and providing a foundation for normal cortical functioning. Moreover, during postnatal development myelin content shows a dramatic increase across the whole brain, starting in thalamocortical and cerebellar structures and eventually reaching phylogenetically newer structures (Davison and Dobbing, 1966; Deoni et al., 2012). The rate and extent of myelination is modulated by functional interneuronal activity (Demerens et al., 1996). Based on the spatiotemporal relationship between evolving cognitive ability and myelination of subserving networks (Johnson and Munakata, 2005; Fornari et al., 2007), asymmetries in myelination may be anticipated to mark specialized cortical circuit foundation generally, and functional lateralization in language specifically. However, there is a significant gap in the imaging literature with respect to children aged between 1 and 6 years due to the inherent difficulty in scanning children in this age group. This is an important period of anatomical neurodevelopment that corresponds to a dramatic period of language expansion (Aslin and Schlaggar, 2006; Dehaene-Lambertz et al., 2006; Pujol et al., 2006). 
Table 1. Sample characteristics by age group

\begin{tabular}{lcllcc}
\hline Age group & N female & N male & N & $\begin{array}{l}\text { Age in days } \\
\text { (range) }\end{array}$ & $\begin{array}{l}\text { Age in days } \\
\text { (mean) }\end{array}$ \\
\hline 1-2 years & 17 & 17 & 34 & $369-724$ & 530.6 \\
2-3 years & 8 & 16 & 24 & $745-1094$ & 918.7 \\
3-4 years & 3 & 12 & 15 & $1095-1451$ & 1302.7 \\
4-5 years & 11 & 11 & 22 & $1501-1809$ & 1680.0 \\
5-6 years & 3 & 10 & 13 & $1859-2199$ & 2012.5 \\
\hline
\end{tabular}

To investigate developmental asymmetry in human brain myelination, we measured myelin content in a large sample of 108 typically developing infants and young children, aged between 1 and 6 years. Quantitative voxelwise myelin water content was measured using multicomponent relaxometry, a technique that estimates myelin-associated water content in white matter (Deoni et al., 2013) and results in a proportion of myelinassociated water for each voxel in the brain (the myelin water fraction, MWF). Our analysis tested the following three specific hypotheses: (1) that leftward asymmetry of myelin content would be evident in lateral temporal and perisylvian areas, (2) that these asymmetries change over time, and (3) that leftward asymmetries would relate to language ability in these children.

\section{Materials and Methods}

Sample. The local institutional review board approved this study and informed consent was obtained from each participating family. One hundred and eight healthy toddlers and young children aged 1 to 6 years (42 female, mean age 3.11 years) born at term took part in this study. For a detailed breakdown per age group see Table 1 .

Cognitive assessment. Within one calendar week of the magnetic resonance imaging (MRI) session, participating children were cognitively assessed using the Mullen Scales of Early Learning (Mullen, 1995), a standardized measure of cognitive ability in infants and young children. There are five subscales in this measure: receptive language, expressive language, gross motor skill, fine motor skill, and visual reception. Here we focus on receptive and expressive language, fine motor, and visual reception subtests as the gross motor scale only covers a portion of the age-range sampled here. The receptive language scale measures auditory and mixed auditory/visual comprehension, expressive language measures early speech proficiency, visual reception broadly measures visual discrimination and memory, and fine motor measures unilateral and bilateral manual manipulation in response to visual cues. The Mullen scales demonstrate good convergent validity with other pediatric cognitive measures (Bishop et al., 2011) and good test-retest stability (Mullen, 1995; Dietz et al., 2007). Handedness was assessed simply using parental questionnaire as part of a medical history questionnaire ("Does your child show a preference for handedness?" "If so which hand?").

Measuring myelin using the MWF. In vivo measurement of myelin is here calculated using multicomponent relaxometry of MRI data (Whittall et al., 1997). Multiple variants of this technique exist but in general the purpose of such techniques is to take advantage of the fact that water has different longitudinal $\left(\mathrm{T}_{1}\right)$ and transverse relaxation time $\left(\mathrm{T}_{2}\right)$ characteristics depending on its environment (Levesque et al., 2010). Specifically, water trapped between the myelin lipid bilayers tends to have a shorter $\mathrm{T}_{2}$ time compared with that of intra/extra cellular water and CSF. Validation of this approach comes largely from models of white matter pathology such as the shiver mouse (Hurley et al., 2010) and multiple sclerosis in humans (Kolind et al., 2012), where localized or global reductions in myelin have been reflected by similar reductions in MWF. Similar approaches to modeling MWF using MRI have also shown strong correspondence to histological staining using luxol fast blue in both demyelinated white matter, normal-appearing white matter, and cortical myelin (Laule et al., 2006, 2008).

For these reasons, the MWF is likely to be more specific to myelin than white matter architectural techniques such as diffusion tensor imaging. Though extremely sensitive to changes in white matter architecture, changes in diffusion tensor-derived indices are extremely difficult to attribute to myelin (Jones and Cercignani, 2010). There is little correlation between fractional anisotropy and MWF in healthy white matter (Kolind et al., 2008) though in multiple sclerosis lesions they correlate indicating that although diffusion tensor imaging-derived indices may be sensitive to myelin, they are unlikely to be specific.

MRI data acquisition. Subject data were acquired either during natural sleep (for children $<4$ years old) or while the child quietly watched a movie. Acquisition parameters were optimized for age group allowing the scan to be kept quiet by reducing slew rates for sleeping toddlers and tolerable for the older children (Deoni et al., 2012). To quantitatively map myelin content we used a multicomponent decomposition of $\mathrm{T}_{1}$ and $\mathrm{T}_{2}$ relaxation (multicomponent driven equilibrium single pulse observation of $\mathrm{T}_{1}$ and $\mathrm{T}_{2}$ or mcDESPOT; Deoni et al., 2008). This method derives MWF from a series of 8 spoiled gradient echo (SPGR) and 16 balanced steady-state free precession (bSSFP) volumes acquired over a range of flip angles. Along with the SPGR images, two inversion recovery SPGR (IR-SPGR) volumes were used to correct for transmit $\left(B_{1}\right)$ magnetic field inhomogeneities; while two bSSFP phase-cycling patterns $(0$ and $180^{\circ}$ ) were acquired for main $\left(B_{0}\right)$ magnetic field inhomogeneity correction (Deoni, 2011). Four age-specific sequences were used here as described in more detail in Deoni et al. (2012). The parameters according to age group are detailed in Table 2. The field of view used was informed by the mean head circumference expected by the child's age (www.cdc. gov/growthcharts/clinical_charts.htm). The image matrix was also altered to provide isotropic voxel sizes of $1.8 \mathrm{~mm}$. Scan time was kept within a tolerable $30 \mathrm{~min}$.

Image preprocessing. To correct for any residual interscan motion, the SPGR, IR-SPGR, and bSSFP images were linearly coregistered to each other using the FSL image registration package flirt (www.fmrib.ox.ac. uk/fsl; Jenkinson et al., 2002). After removing nonbrain voxels, MWF maps were calculated for each subject at every voxel using a three pool model for water content in white matter (Deoni et al., 2013).

Images were transformed to a common space using a two-stage process. The $\mathrm{T}_{1}$-weighted SPGR image with the highest flip angle was chosen as the image to register as it had the highest tissue contrast. The first stage registered this SPGR to an age-specific $\mathrm{T}_{1}$-weighted template, a necessity for pediatric imaging in this age range due to the rapidly changing $\mathrm{T}_{1-}$ weighted contrast (Deoni et al., 2012; Sadeghi et al., 2013). Nonlinear registrations to this age-specific template were performed using the image registration package ANTS and symmetric diffeomorphic normalization (SyN, implemented in the ANTs package; http://www.picsl.upenn. edu/ANTS/;Avants et al., 2011). A further precalculated transformation was applied from the age-specific template to a pediatric template (Deoni et al., 2012). The SPGR was then flipped on the $x$-axis (sagittally) and this flipped image was registered in the same way to the same pediatric template. These transformations were then applied to the native space MWF and flipped MWF images. Analyses were constrained to a core white matter mask created by averaging the raw and flipped images for all subjects, thresholding by 0.05 for both and only voxels surviving this thresholding in raw and flipped space were kept for further analysis.

The resulting MWF images (flipped and standard) were converted to voxelwise asymmetry indices using the following formula: (Left Right $) /($ Left + Right $)$. The resulting images were smoothed spatially using a 3D Gaussian kernel with a full-width at half maximum of $5 \mathrm{~mm}$ within the white matter mask (3dBlurInMask, part of the AFNI package http://afni.nimh.nih.gov/).

Imaging statistics. A general linear model (GLM) was created using the FSL package GLM. Mean asymmetry, age, and gender were used as predictor variables and contrasts were designed to investigate significant leftward and rightward asymmetry. This GLM was tested nonparametrically using permutation testing (randomize). Images were thresholded using a two-stage procedure with clusters determined at $t<3.1$ (approximately $p<0.001$ ), and a cluster significance level of $p<0.05$, corrected for multiple comparisons.

Post hoc asymmetry/cognition relationships. From the significant clusters of asymmetry detected in the main analysis, mean asymmetry index values were extracted for every subject. To investigate the relationship between these asymmetries and the four Mullen subscales, a series of 
Table 2. mcDESPOT acquisition parameters by age group

\begin{tabular}{lllll}
\hline Age group (months) & $9-16$ & $16-28$ & $28-48$ & $48+$ \\
\hline Acquisition time (min) & $18: 42$ & $21: 38$ & $24: 20$ & $22: 45$ \\
Unprotected dB* & 62 & 69 & 74 & 82 \\
Field of view (cm) & $17 \times 17 \times 14.4$ & $18 \times 18 \times 15$ & $20 \times 20 \times 15$ & $20 \times 20 \times 16.5$ \\
SPGR TE/TR (ms) & $5.9 / 12$ & $5.4 / 12$ & $5.2 / 11$ & $4.8 / 10$ \\
SPGR flip angles & $2,3,4,5,7,9,11,14$ & $2,3,4,5,7,9,11,14$ & $2,3,4,5,7,9,12,16$ & $3,4,5,6,7,9,12,16$ \\
IR-SPGR inversion time (ms) & 600900 & 500850 & 500800 & 450750 \\
bSSFP TE/TR (ms) & $5.1 / 10.2$ & $5 / 10$ & $4.4 / 9.8$ & $5 / 10$ \\
bSSFP flip angles & $9,14,20,27,34,41,56,70$ & $9,14,20,27,34,41,56,70$ & $9,14,20,27,34,41,56,70$ & $9,14,20,27,34,41,56,70$ \\
\hline
\end{tabular}

Table 3. Handedness and cognitive summary scores by gender

\begin{tabular}{lllll}
\hline$N$ & Male & Female & Total valid & $p$ value \\
& 67 & 41 & 108 & \\
\hline Handedness & & & & \\
$\quad$ Left & 7 & 5 & 12 & \\
$\quad$ Right & 42 & 23 & 65 & \\
$\quad$ No preference & 13 & 11 & 24 & \\
$\quad$ Missing & 4 & 3 & 7 & $0.65^{*}$ \\
Cognitive measures (scaled scores) & & & & \\
$\quad$ Fine motor & $49.3(10.5)$ & $55(12.6)$ & 103 & $0.224^{* *}$ \\
$\quad$ Visual reception & $53.5(10.9)$ & $46.9(9.2)$ & 103 & $0.301^{* *}$ \\
$\quad$ Receptive language & $51.9(12)$ & $53.2(11.8)$ & 102 & $0.596^{* *}$ \\
$\quad$ Expressive language & $49.5(11.6)$ & $51(10)$ & 99 & $0.504^{* *}$ \\
\hline
\end{tabular}

*Comparisons between males and females assessed using $\chi^{2}$ test. ${ }^{* *}$ Comparisons between males and females assessed using Independent Sample $t$ test.

GLMs were created in SPSS (SPSS, IBM). The predictors of cognitive abilities were mean asymmetry values underlying the significant results of the voxelwise analysis, age, gender, handedness, and the interactions of asymmetry with age. We corrected for multiple comparisons using false discovery rate (Benjamini and Hochberg, 1995) at both levels.

To illustrate an age*asymmetry interaction in predicting cognitive scores, we plotted a moving average correlation of language score and asymmetry index as a function of a moving age bin centered on each subject's age. The number of subjects for each bin was held constant (12 younger and 12 older), though the age range varied. This was performed purely to illustrate any significant interactions in the relationship between asymmetry and cognitive ability with age.

\section{Results}

Descriptive statistics related to handedness and results on the cognitive subscales are outlined in Table 3. No significant differences were detectable between genders. Mullen scales are designed to have a mean of 50 and an SD of 10 . Our results roughly reflect this, indicating our sample is representative of a typical population of infants and toddlers. However, there was a ceiling effect in the scores for children at the top end of the age range (see Fig. 1 for a plot of raw and scaled scores as a function of age; children aged $>1800 \mathrm{~d}$ are marked in red). This ceiling effect is partly reflected in the Mullen Scales manual (Mullen, 1995) by a reduction in the possible range of scaled scores in later childhood. We reproduce this ceiling and reduction in range here (Fig. 1, bottom row, red).

\section{Asymmetry of myelin content}

A whole-brain voxelwise analysis of myelin content asymmetry was tested by permutation within a white matter mask (Fig. 2, blue outline). Significant leftward asymmetry (Fig. 2, top row) was detected in clusters in the anterior caudate and thalamus, medial frontal cortex (a region that corresponds to the white matter projections of the anterior thalamus as well as the anterior aspect of the cingulum bundle), posterior parietal lobe, and a single cluster in the temporal/occipital lobe that overlaps with the trajectory of the inferior longitudinal fasciculus and the arcuate fasciculus. Rightward asymmetry was detected in the dorsal aspect of the extreme capsule, white matter underlying lateral motor cortex (corresponding to the mouth area), and ventral frontal cortex (Fig. 2, bottom row). Further contrasts were designed to investigate the effect of age and gender on this asymmetry. No significant relationships were detected. Our data indicate that although absolute MWF in these regions is increasing, as would be expected (Deoni et al., 2012; Fig. 3c), the asymmetry of myelination is relatively constant, with no significant change over time (Fig. $3 d$ ). Mean asymmetry results and their coordinates in standard (MNI) space are in detailed in Table 4.

\section{Relationship of asymmetry to language ability}

To investigate relationships between the above structural asymmetries and expressive and receptive language ability, we created a multivariate GLM with gender, age, and asymmetry index (of the eight clusters detected in the asymmetry analysis) and their interactions with age as predictors of the four cognitive measures. Results from this analysis revealed a positive relationship between leftward asymmetry in the anterior thalamus and caudate with receptive language $(F=8.720, \mathrm{df}=1,71, p<0.004)$ and visual reception scores $(F=7.389$, df $=1,71, p<0.008)$. Rightward asymmetry in the extreme capsule was associated with receptive language scores $(F=16.383, \mathrm{df}=1,71, p<0.001)$ as well as expressive language $(F=4.903, \mathrm{df}=1,71, p<0.030)$. A negative relationship was detected between leftward medial frontal asymmetry and expressive language ability $(F=6.932 \mathrm{df}=1,71, p<$ 0.01 ). No relationship was detected between lateral frontal or temporal areas and these language measures. Importantly, a significant interaction was detected between the relationship of asymmetry and language with age. In fact, looking at Figure 4, not just the strength, but the directionality of the relationships changes with age. With age, the relationship between rightward asymmetry in the putamen and receptive language starts negative but becomes progressively positive $(F=14.345$, df $=1,71, p<$ $0.001)$ and the same pattern is evident with expressive language $(F=5.836, \mathrm{df}=1,71, p<0.018)$, albeit to a weaker extent (Fig. 4 , top row). Leftward asymmetry in frontal cortex shows a negative relationship in infants but becomes progressively positive $(F=7.782, \mathrm{df}=1,71, p<0.007)$, whereas leftward asymmetry in the anterior thalamus/caudate starts positive and becomes progressively negative $(F=9.441$, $\mathrm{df}=1,71, p<0.007$; Fig. 4 , bottom row). These results are summarized in Table 4. Omission of children aged $>1800 \mathrm{~d}$ (i.e., at the ceiling for behavioral scores) did not alter these results.

\section{Discussion}

Using a novel quantitative measure of myelin content, we investigated asymmetry of myelination in the developing brain, focusing on a challenging and understudied age group of typically 


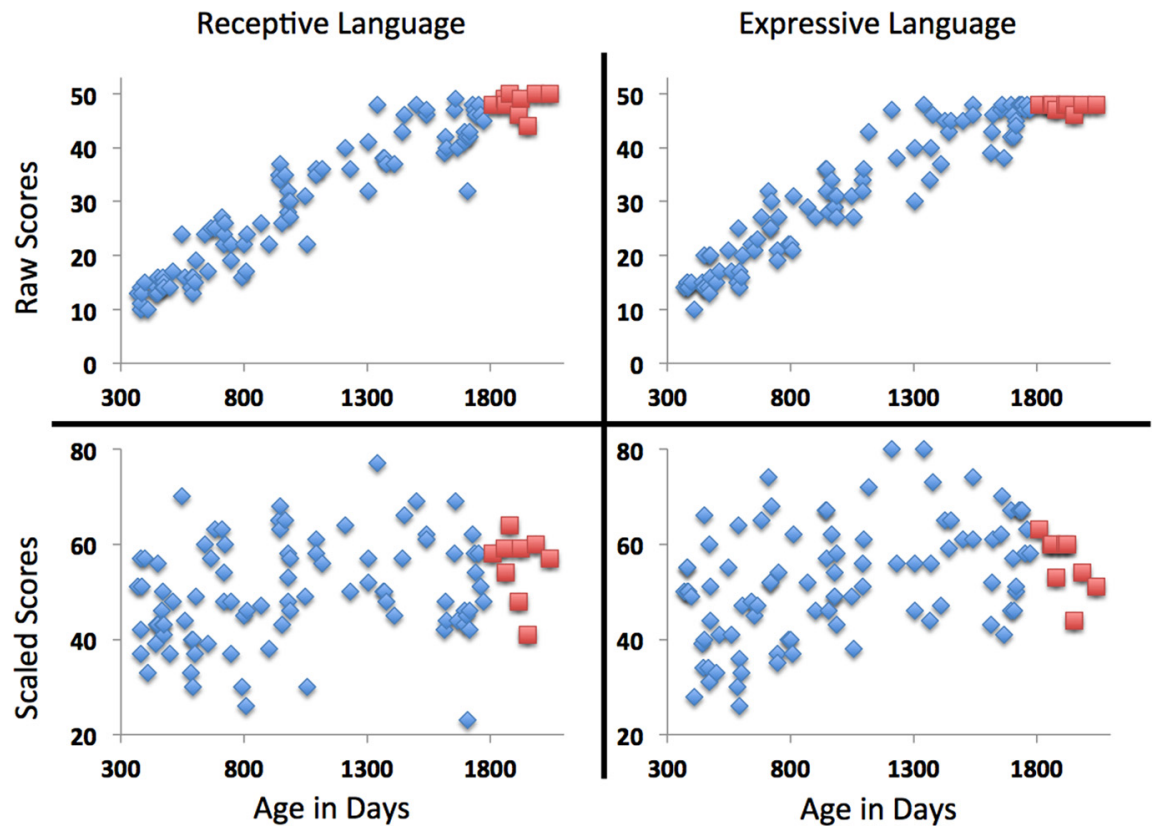

Figure 1. Plots of raw scores (top row) and scaled scores (bottom row) of receptive language (left column) and expressive language (right column) against age. A marked ceiling effect in the raw scores is evident in children aged over 1800 days (highlighted in red) and is reflected by a reduced spread in scaled scores.

developing toddlers and young children. Although we expected significant asymmetry in white matter regions underlying classical language areas such as the arcuate fasciculus interconnecting Broca's area in the frontal lobe and the planum temporale (Toga and Thompson, 2003), we detected a more spatially and anatomically extensive set of asymmetries. The degree of asymmetry in these regions appears constant with age, in contrast to what would be predicted by functional (Dehaene-Lambertz et al., 2006) though not necessarily morphological or anatomical (Hill et al., 2010) studies.

We detected relationships between the asymmetry and visual, receptive language and expressive language abilities in these same young children. Unlike the asymmetries themselves, this relationship changed both in strength and direction over time. Combined, these results bridge a gap between recent reports of structure in children and infants, revealing the changing functional relationships occurring in the connectional white matter of the brain in this practically challenging and understudied population of infants and toddlers. This white matter asymmetry uses a biologically plausible and quantitative marker of myelin, allowing us to be more specific in our biological interpretation than is possible in volumetry or diffusion data analysis (Jones and Cercignani, 2010).

The change and progression of language abilities in this age range is dramatic. Children develop from a limited receptive vocabulary of up to 50 words at one year to a vocabulary of $\sim 5000$ words at 6 years (Locke, 1997). The fastest lifetime rate of both expressive and receptive language acquisition occurs between 18 and 60 months, slowing thereafter. This sample captures this period of intense development, providing a novel view on the anatomical architecture supporting this linguistic development. Our results emphasize the critical role of subcortical structures in the architecture of early language development. This is perhaps unsurprising given that these structures are among the first to myelinate (Brody et al., 1987; Hasegawa et al., 1992). The areas reported here, part of cohesive thalamo-cortico-basal ganglial circuits (Alexander and Crutcher, 1990), are strongly associated with language ability (Barbas et al., 2013); the anterior thalamus especially in linguistic violation processing (Wahl et al., 2008) and the left caudate in language monitoring (Ali et al., 2010). Rightward asymmetry in the extreme capsule superior to the putamen may reflect connectivity to lateral frontal cortex. The putamen specifically has been associated functionally with frontal areas during phonological processing (Booth et al., 2007) and more generally with respect to motor control in language (Jürgens, 2002).

It is possible that leftward asymmetry of mesial frontal cortex is anatomically related to the thalamic and caudate myelin asymmetry as it overlaps spatially with thalamofrontal projections (Fair et al., 2010; O'Muircheartaigh et al., 2011). However, this is unlikely given their differing relationship and direction with language abilities (Fig. 4). This frontal region also overlaps with the anterior aspect of the cingulum bundle, argued to be a critical region involved in attention (Posner, 2012). The cingulum myelinates relatively late (Fuster, 2002; Fields, 2005), possibly going some way to explain the flip in relationship from positive to negative relationship with language between 1 and 4 years. The association between this region and expressive language ability may be dependent on other more general underlying processes. Asymmetry in this region did not show any relationship with visual reception scores, a specific measure of visual attention. The association between mesial frontal cortex and social learning (Amodio and Frith, 2006), a precondition to successful language acquisition (Kuhl, 2007), may therefore be more relevant.

Although we did detect asymmetry in this age group in areas that overlap with areas classically associated with language, such as the ventral aspect of the arcuate fasciculus, we did not detect a relationship with language. Relationships described in adults have not specifically been shown with language, but with verbal recall (Catani et al., 2007), and asymmetry of tractographyderived streamlines in the arcuate showed a marked ceiling effect with a significant proportion of children showing 100\% leftward asymmetry (i.e., no right arcuate fasciculus; Lebel and Beaulieu, 2009). Using fractional anisotropy, a measure of white matter fiber architecture, asymmetries in the arcuate fasciculus have been also shown in infants (Dubois et al., 2009). Though not discussed in detail, leftward asymmetries in areas relevant here such as the anterior thalamus, mesial frontal cortex and rightward asymmetries in the anterior insula were also detected. These results are unlikely to be related to myelination, as this area is weakly myelinated in the infant age group investigated (Brody et al., 1987). Instead they may demonstrate asymmetries in the underlying fiber architecture, the structural foundation upon which myelination occurs.

Although functional asymmetry changes during early childhood, becoming progressively more lateralized (DehaeneLambertz et al., 2006), the magnitude of asymmetry of myelin here remains constant (Fig. $3 d$ ). However, the relationship between myelin asymmetry and language changed over time. Im- 


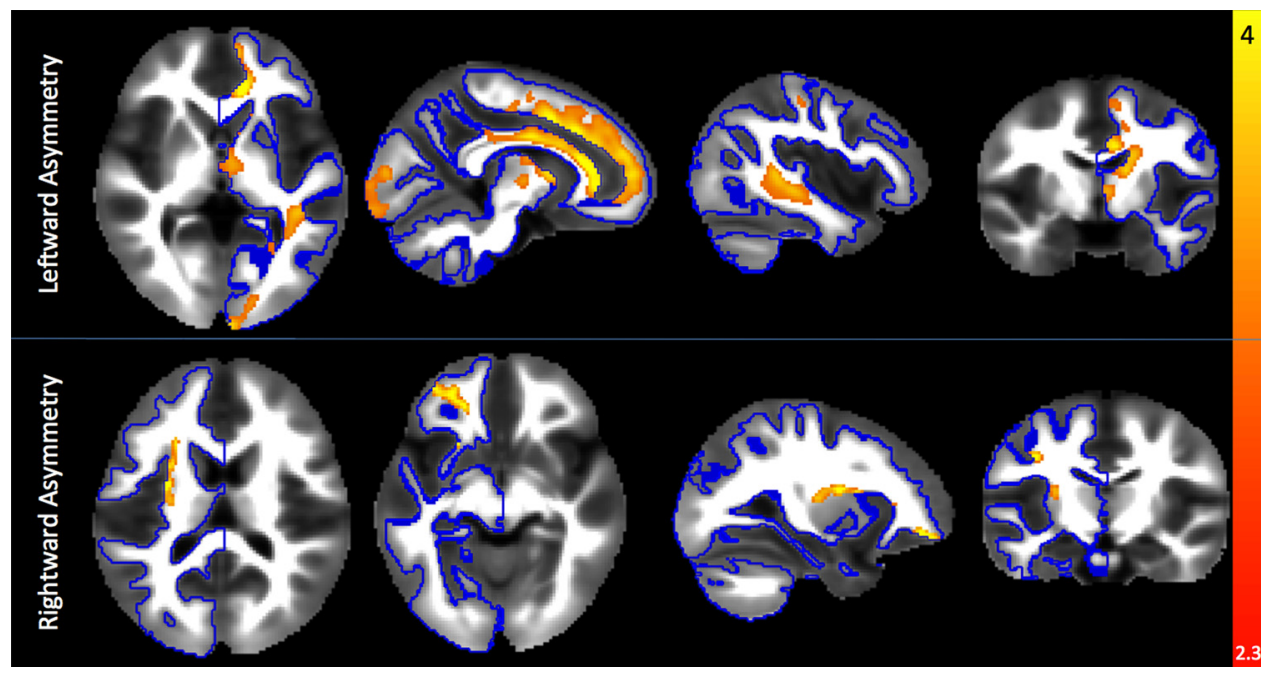

Figure 2. Results of the voxelwise asymmetry results overlaid on an average MWF volume. The blue outline presents the area within which the voxelwise tests were performed. Red-yellow regions indicate regions of significant ( $p<0.05$, corrected for multiple comparisons and tests) leftward (top row) and rightward (bottom row) asymmetry of the MWF, a quantitative estimate of myelin-associated water.

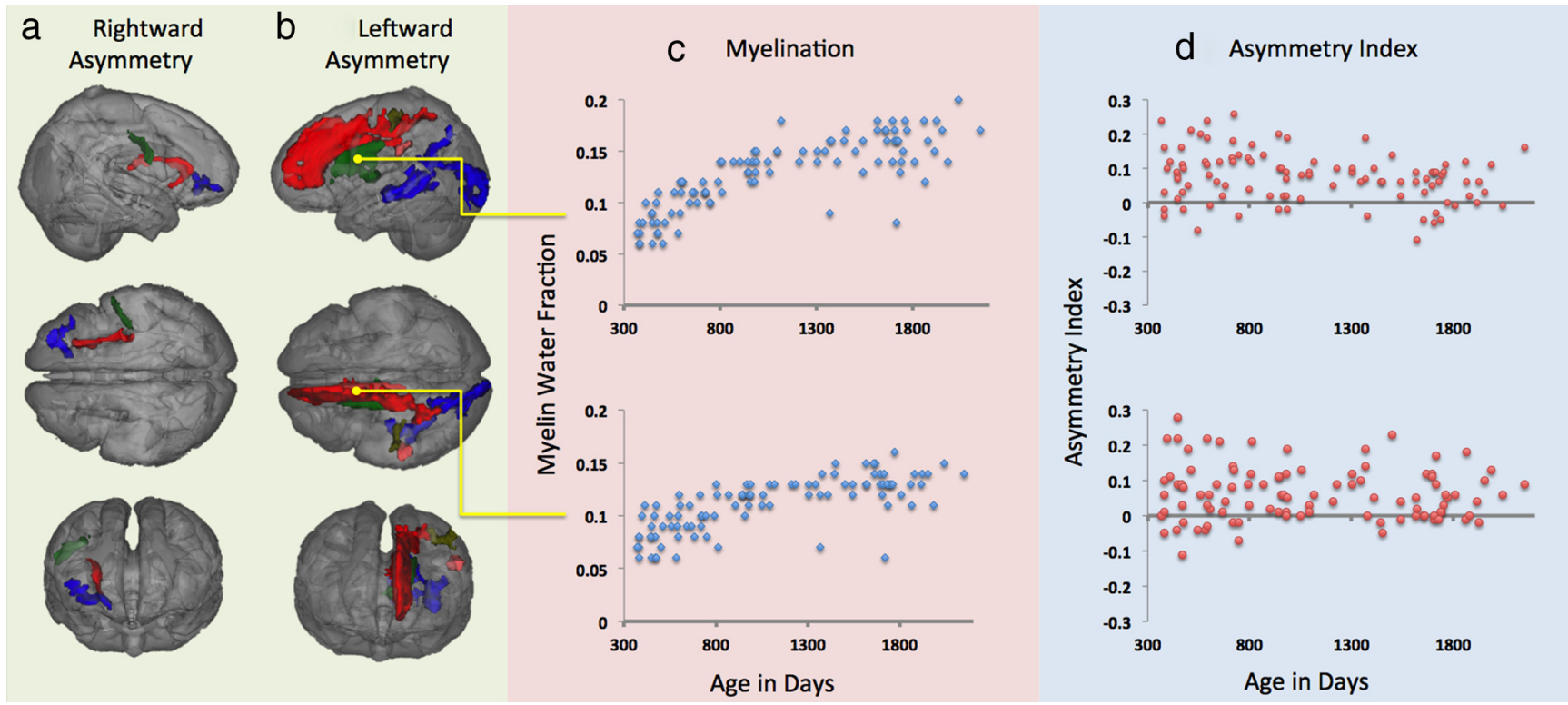

Figure 3. Significant asymmetry results rendered as a volume. Rightward asymmetry (a) was detected in ventrolateral frontal cortex (blue), putamen and external capsule (red), and lateral postcentral cortex (green). Leftward asymmetry (b) was detected in the anterior cingulate, extending to mesial frontal cortex (red), anterior thalamus and caudate (green), postcentral gyrus (yellow), temporoparietal junction (yellow), and temporal and occipital areas (blue). $\boldsymbol{c}$, Shows the relationship between age and myelination (blue diamonds) and (d) asymmetry (red circles) for the anterior thalamus region (top) and the mesial frontal region (bottom). Note that positive values reflect leftward asymmetry and negative values rightward.

portantly this changing relationship appears to stabilize at $\sim 3-4$ years (Fig. 4), around the same time that myelin development begins to slow substantially (Fig. $3 c$ ) and overlapping with the end of a putative language critical period (Locke, 1997). This may reflect the more intense functional asymmetry occurring in language networks in this age group, and therefore the higher importance attributed to white matter underlying a functional area.

For the putamen and mesial frontal areas, asymmetry initially negatively predicts language ability in the young toddlers, but eventually positively predicts language in the older children and vice versa in the medial frontal lobe. The change in direction of the relationship between language and asymmetry is puzzling although not unique. This flip in directionality has been observed before in older children (Shaw et al., 2006; Fjell et al., 2012). Children with high intelligence initially had relatively thinner cortex compared with those of average intelligence but by their teens had demonstrably thicker cortex in medial frontal gray matter overlapping with that detected here. Fjell et al. (2012) found that the right anterior cingulate area was related to cognitive control in children aged four years and above. This relationship changed over age from a negative influence to a positive. Our leftward asymmetry relates to language in a similar way, indicating that the influence of this region of the brain may not be specific to language but more generally to cognitive control. Although investigating older children and gray matter, these results imply differential recruitment of anatomical pathways to support cognitive ability during development. Investigations of younger groups have demonstrated extensive postnatal changes in cortical gray matter (Dubois et al., 2010) with early indications of subcortical structure in infancy positively predicting later language skills 
Table 4. Summary of the main results, asymmetry indices, and coordinates in MNI space

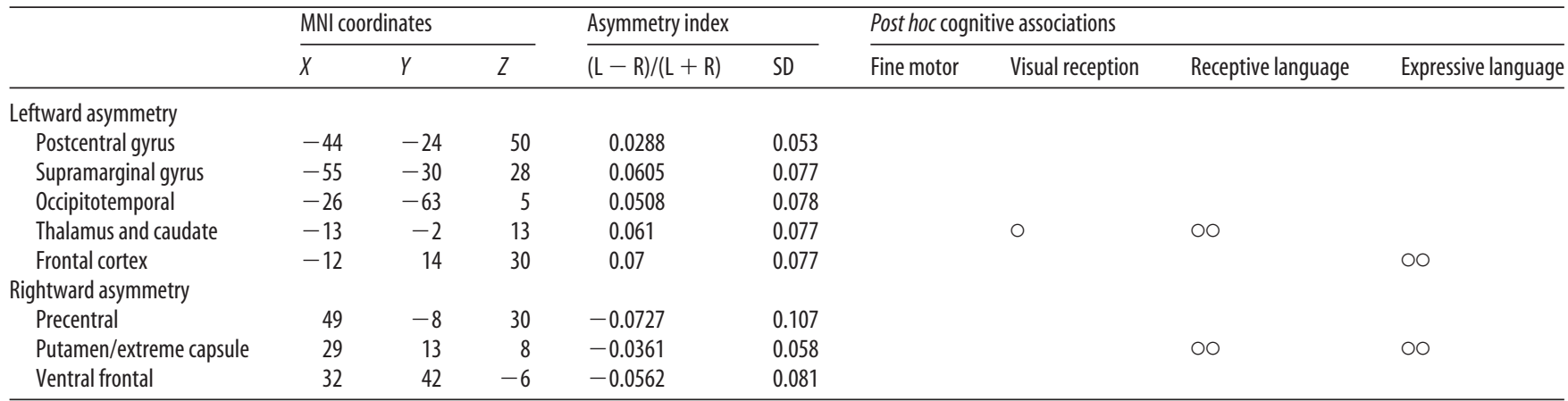

O, Association with Cognitive Scale only; $\bigcirc \circ$, association with Cognitive Scale as well as a significant interaction in this relationship with age. All significant relationships are reported with df $=71,1, p<0.05, q<0.05$.

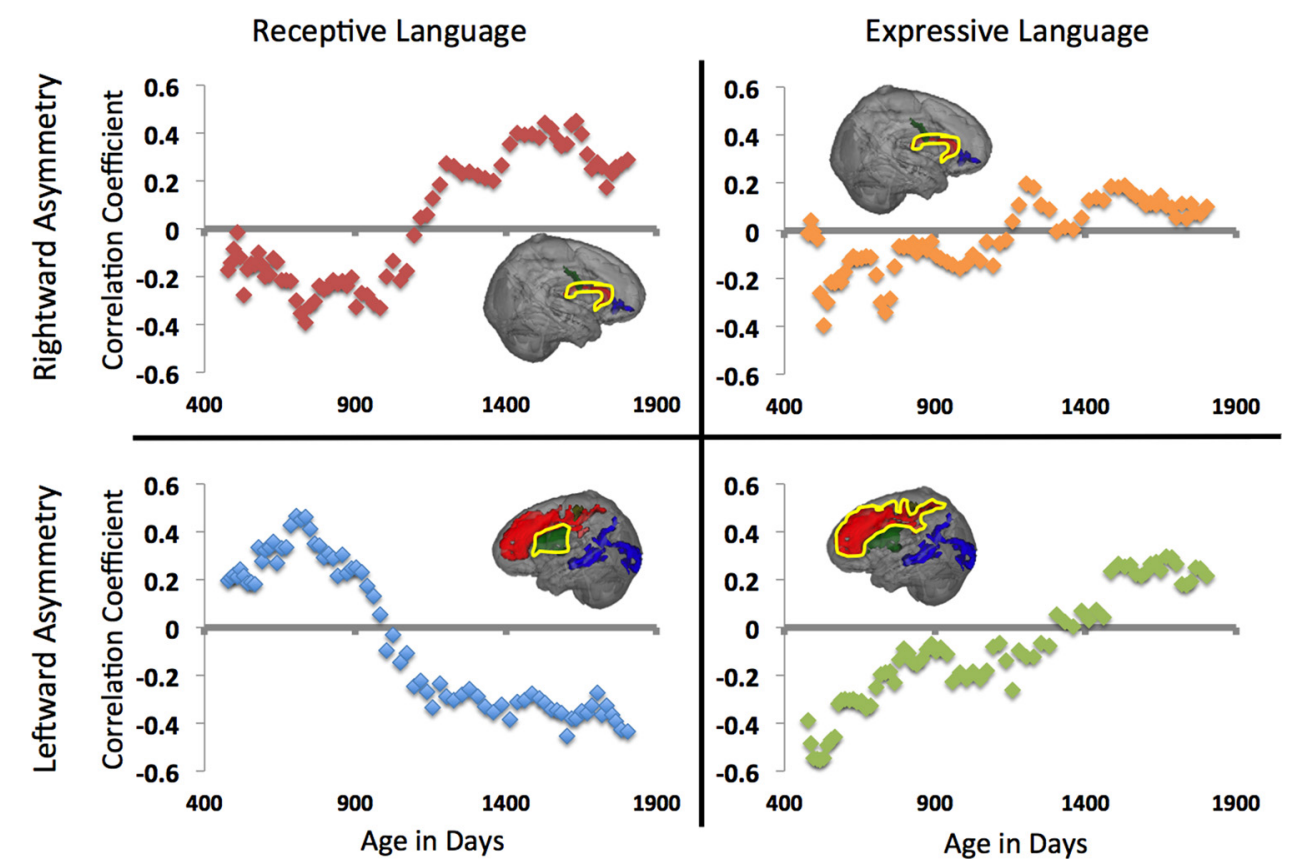

Figure 4. Moving average correlations (Pearson's $r ; y$-axis) as a function of age (in days; $x$-axis). Plots demonstrate the changing relationships between asymmetry of myelin content in the extreme capsule and receptive and expressive language scores, respectively (top row), and between leftward asymmetry in the caudate/thalamus and frontal cortex with receptive and expressive language scores respectively (bottom row).

(Deniz Can et al., 2013). The data presented here are cross sectional, longitudinal analysis will allow us to confirm these findings; however, the changing interaction between ability and myelin may be mediated by progressive functional specialization in these connected cortical regions, which itself is partly mediated by environmental influences (Johnson, 2001).

Deviations from typical patterns of cortical and functional asymmetry have been related to autism (Eyler et al., 2012), developmental language disorders (Herbert et al., 2005), and schizophrenia (Kawasaki et al., 2008). These neurodevelopmental disorders have been characterized within the framework of white matter disconnectivity (Catani and ffytche, 2005; Fields, 2008). A characterization of typical patterns of asymmetry would help pinpoint where and when these disorders deviate from normal patterns of development. In infants with autism, functional MRI studies have revealed an absence of leftward functional asymmetry in response to language in the superior temporal gyrus. It was shifted significantly rightward (i.e., abnormally) as a function of age (Eyler et al., 2012). This functional finding is mirrored by a shift of gray matter asymmetry from left to right in adolescents with developmental language disorder and autism (Herbert et al., 2005). Reduced asymmetry of the planum temporale has also been reported in dyslexia (Beaton, 1997). What is not clear is whether these asymmetries are a consequence rather than a cause of these disorders (Bishop, 2013). Myelin content is particularly suited to track these changes and answer these questions. In children, myelination goes through a dramatic and stereotyped pattern of development (Davison and Dobbing, 1966; Deoni et al., 2012) and occurs in response to activity (Demerens et al., 1996) as well as shaping functional activity (Fornari et al., 2007). Therefore changes in neuronal activity would be expected to precede and predict changes in myelination.

Using a large cross-sectional sample of infants and toddlers and a novel in vivo approach to the quantification of water myelin content, we demonstrate that, while cerebral asymmetry may be established and constrained at an early age, this asymmetry is related to language ability in children undergoing a crucial period of neuroanatomical development. Importantly, the coupling between asymmetrical structure and function changes during development and this flux in relations between anatomy and language stabilizes around the age of 4 years. This is the first work 
to investigate specific asymmetry of myelin, providing a new outlook on the developing brain and the interaction between white matter anatomy and developing cognition.

\section{References}

Alexander GE, Crutcher MD (1990) Functional architecture of basal ganglia circuits: neural substrates of parallel processing. Trends Neurosci 13:266271. CrossRef Medline

Ali N, Green DW, Kherif F, Devlin JT, Price CJ (2010) The role of the left head of caudate in suppressing irrelevant words. J Cogn Neurosci 22: 2369-2386. CrossRef Medline

Amodio DM, Frith CD (2006) Meeting of minds: the medial frontal cortex and social cognition. Nat Rev Neurosci 7:268-277. CrossRef Medline

Aslin RN, Schlaggar BL (2006) Is myelination the precipitating neural event for language development in infants and toddlers? Neurology 66:304305. CrossRef Medline

Avants BB, Tustison NJ, Song G, Cook PA, Klein A, Gee JC (2011) A reproducible evaluation of ANTs similarity metric performance in brain image registration. Neuroimage 54:2033-2044. CrossRef Medline

Barbas H, García-Cabezas MÁ, Zikopoulos B (2013) Frontal-thalamic circuits associated with language. Brain Lang 126:49-61. CrossRef Medline

Beaton AA (1997) The relation of planum temporale asymmetry and morphology of the corpus callosum to handedness, gender, and dyslexia: a review of the evidence. Brain Lang 60:255-322. CrossRef Medline

Benjamini Y, Hochberg Y (1995) Controlling the false discovery rate: a practical and powerful approach to multiple testing. J R Stat Soc Ser B Methodol 57:289-300.

Bishop DVM (2013) Cerebral asymmetry and language development: cause, correlate, or consequence? Science 340:1302-1310. CrossRef

Bishop SL, Guthrie W, Coffing M, Lord C (2011) Convergent validity of the Mullen scales of early learning and the differential ability scales in children with autism spectrum disorders. Am J Intellect Dev Disabil 116:331-343. CrossRef Medline

Booth JR, Wood L, Lu D, Houk JC, Bitan T (2007) The role of the basal ganglia and cerebellum in language processing. Brain Res 1133:136-144. CrossRef Medline

Bradshaw JL (1978) Human cerebral asymmetry. Trends Neurosci 1:113116. CrossRef

Brody BA, Kinney HC, Kloman AS, Gilles FH (1987) Sequence of central nervous system myelination in human infancy. I. An autopsy study of myelination. J Neuropathol Exp Neurol 46:283-301. CrossRef Medline

Casey BJ, Tottenham N, Liston C, Durston S (2005) Imaging the developing brain: what have we learned about cognitive development? Trends Cogn Sci 9:104-110. CrossRef Medline

Catani M, ffytche DH (2005) The rises and falls of disconnection syndromes. Brain 128:2224-2239. CrossRef Medline

Catani M, Allin MP, Husain M, Pugliese L, Mesulam MM, Murray RM, Jones DK (2007) Symmetries in human brain language pathways correlate with verbal recall. Proc Natl Acad Sci U S A 104:17163-17168. CrossRef Medline

Davison AN, Dobbing J (1966) Myelination as a vulnerable period in brain development. Br Med Bull 22:40-44. Medline

Dehaene-Lambertz G, Hertz-Pannier L, Dubois J (2006) Nature and nurture in language acquisition: anatomical and functional brain-imaging studies in infants. Trends Neurosci 29:367-373. CrossRef Medline

Demerens C, Stankoff B, Logak M, Anglade P, Allinquant B, Couraud F, Zalc B, Lubetzki C (1996) Induction of myelination in the central nervous system by electrical activity. Proc Natl Acad Sci U S A 93:9887-9892. CrossRef Medline

Deniz Can D, Richards T, Kuhl PK (2013) Early gray-matter and whitematter concentration in infancy predict later language skills: a whole brain voxel-based morphometry study. Brain Lang 124:34-44. CrossRef Medline

Deoni SC (2011) Correction of main and transmit magnetic field (B0 and B1) inhomogeneity effects in multicomponent-driven equilibrium single-pulse observation of T1 and T2. Magn Reson Med 65:1021-1035. CrossRef Medline

Deoni SC, Rutt BK, Arun T, Pierpaoli C, Jones DK (2008) Gleaning multicomponent $\mathrm{T} 1$ and $\mathrm{T} 2$ information from steady-state imaging data. Magn Reson Med 60:1372-1387. CrossRef Medline

Deoni SC, Dean DC 3rd, O’Muircheartaigh J, Dirks H, Jerskey BA (2012) Investigating white matter development in infancy and early childhood using myelin water faction and relaxation time mapping. Neuroimage 63:1038-1053. CrossRef Medline

Deoni SC, Matthews L, Kolind SH (2013) One component? Two components? Three? The effect of including a nonexchanging "free" water component in multicomponent driven equilibrium single pulse observation of T1 and T2. Magn Reson Med 70:147-154. Medline

Dietz C, Swinkels SH, Buitelaar JK, van Daalen E, van Engeland H (2007) Stability and change of IQ scores in preschool children diagnosed with autistic spectrum disorder. Eur Child Adolesc Psychiatry 16:405-410. CrossRef Medline

Dubois J, Hertz-Pannier L, Cachia A, Mangin JF, Le Bihan D, DehaeneLambertz G (2009) Structural asymmetries in the infant language and sensori-motor networks. Cereb Cortex 19:414-423. CrossRef Medline

Dubois J, Benders M, Lazeyras F, Borradori-Tolsa C, Leuchter RH, Mangin JF, Hüppi PS (2010) Structural asymmetries of perisylvian regions in the preterm newborn. Neuroimage 52:32-42. CrossRef Medline

Eyler LT, Pierce K, Courchesne E (2012) A failure of left temporal cortex to specialize for language is an early emerging and fundamental property of autism. Brain 135:949-960. CrossRef Medline

Fair DA, Bathula D, Mills KL, Dias TG, Blythe MS, Zhang D, Snyder AZ, Raichle ME, Stevens AA, Nigg JT, Nagel BJ (2010) Maturing thalamocortical functional connectivity across development. Front Syst Neurosci 4:10. Medline

Fields RD (2005) Myelination: an overlooked mechanism of synaptic plasticity? Neuroscientist 11:528-531. CrossRef Medline

Fields RD (2008) White matter in learning, cognition and psychiatric disorders. Trends Neurosci 31:361-370. CrossRef Medline

Fjell AM, Walhovd KB, Brown TT, Kuperman JM, Chung Y, Hagler DJ Jr, Venkatraman V, Roddey JC, Erhart M, McCabe C, Akshoomoff N, Amaral DG, Bloss CS, Libiger O, Darst BF, Schork NJ, Casey BJ, Chang L, Ernst TM, Gruen JR, et al. (2012) Multimodal imaging of the self-regulating developing brain. Proc Natl Acad Sci U S A 109:19620-19625. CrossRef Medline

Fornari E, Knyazeva MG, Meuli R, Maeder P (2007) Myelination shapes functional activity in the developing brain. Neuroimage 38:511-518. CrossRef Medline

Fuster JM (2002) Frontal lobe and cognitive development. J Neurocytol 31: 373-385. CrossRef Medline

Gannon PJ, Holloway RL, Broadfield DC, Braun AR (1998) Asymmetry of chimpanzee planum temporale: humanlike pattern of Wernicke's brain language area homolog. Science 279:220-222. CrossRef Medline

Gilmore JH, Lin W, Prastawa MW, Looney CB, Vetsa YS, Knickmeyer RC, Evans DD, Smith JK, Hamer RM, Lieberman JA, Gerig G (2007) Regional gray matter growth, sexual dimorphism, and cerebral asymmetry in the neonatal brain. J Neurosci 27:1255-1260. CrossRef Medline

Hasegawa M, Houdou S, Mito T, Takashima S, Asanuma K, Ohno T (1992) Development of myelination in the human fetal and infant cerebrum: a myelin basic protein immunohistochemical study. Brain Dev 14:1-6. CrossRef Medline

Herbert MR, Ziegler DA, Deutsch CK, O’Brien LM, Kennedy DN, Filipek PA, Bakardjiev AI, Hodgson J, Takeoka M, Makris N, Caviness VS Jr (2005) Brain asymmetries in autism and developmental language disorder: a nested whole-brain analysis. Brain 128:213-226. Medline

Hill J, Dierker D, Neil J, Inder T, Knutsen A, Harwell J, Coalson T, Van Essen D (2010) A surface-based analysis of hemispheric asymmetries and folding of cerebral cortex in term-born human infants. J Neurosci 30:22682276. CrossRef Medline

Hurley SA, Mossahebi PM, Samsonov AA, Alexander AL, Deoni SC, Fisher R, Duncan ID, Field AS (2010) Multicomponent relaxometry (mcDESPOT) in the shaking pup model of dysmyelination. In Proceedings of the 18th Meeting of the International Society for Magnetic Resonance in Medicine, Stockholm, pp 4516.

Jenkinson M, Bannister P, Brady M, Smith S (2002) Improved optimization for the robust and accurate linear registration and motion correction of brain images. Neuroimage 17:825-841. CrossRef Medline

Johnson MH (2001) Functional brain development in humans. Nat Rev Neurosci 2:475-483. CrossRef Medline

Johnson MH, Munakata Y (2005) Processes of change in brain and cognitive development. Trends Cogn Sci 9:152-158. CrossRef Medline

Jones DK, Cercignani M (2010) Twenty-five pitfalls in the analysis of diffusion MRI data. NMR Biomed 23:803-820. CrossRef Medline 
Jürgens U (2002) Neural pathways underlying vocal control. Neurosci Biobehav Rev 26:235-258. CrossRef Medline

Kawasaki Y, Suzuki M, Takahashi T, Nohara S, McGuire PK, Seto H, Kurachi M (2008) Anomalous cerebral asymmetry in patients with schizophrenia demonstrated by voxel-based morphometry. Biol Psychiatry 63:793800. CrossRef Medline

Keller SS, Crow T, Foundas A, Amunts K, Roberts N (2009) Broca's area: nomenclature, anatomy, typology and asymmetry. Brain Lang 109:2948. CrossRef Medline

Kolind SH, Laule C, Vavasour IM, Li DK, Traboulsee AL, Mädler B, Moore GR, Mackay AL (2008) Complementary information from multiexponential T2 relaxation and diffusion tensor imaging reveals differences between multiple sclerosis lesions. Neuroimage 40:77-85. CrossRef Medline

Kolind S, Matthews L, Johansen-Berg H, Leite MI, Williams SC, Deoni S, Palace J (2012) Myelin water imaging reflects clinical variability in multiple sclerosis. Neuroimage 60:263-270. CrossRef Medline

Kuhl PK (2007) Is speech learning "gated" by the social brain? Dev Sci 10: 110-120. CrossRef Medline

Laule C, Leung E, Lis DK, Traboulsee AL, Paty DW, MacKay AL, Moore GR (2006) Myelin water imaging in multiple sclerosis: quantitative correlations with histopathology. Mult Scler 12:747-753. CrossRef Medline

Laule C, Kozlowski P, Leung E, Li DK, Mackay AL, Moore GR (2008) Myelin water imaging of multiple sclerosis at $7 \mathrm{~T}$ : correlations with histopathology. Neuroimage 40:1575-1580. CrossRef Medline

Lebel C, Beaulieu C (2009) Lateralization of the arcuate fasciculus from childhood to adulthood and its relation to cognitive abilities in children. Hum Brain Mapp 30:3563-3573. CrossRef Medline

Levesque IR, Chia CL, Pike GB (2010) Reproducibility of in vivo magnetic resonance imaging-based measurement of myelin water. J Magn Reson Imaging 32:60-68. CrossRef Medline

Locke JL (1997) A theory of neurolinguistic development. Brain Lang 58: 265-326. CrossRef Medline

Mullen EM (1995) Mullen scales of early learning (AGS ed). Circle Pines, $\mathrm{MN}$ : American Guidance Service.
O’Muircheartaigh J, Vollmar C, Traynor C, Barker GJ, Kumari V, Symms MR, Thompson P, Duncan JS, Koepp MJ, Richardson MP (2011) Clustering probabilistic tractograms using independent component analysis applied to the thalamus. Neuroimage 54:2020-2032. CrossRef Medline

Passingham RE, Stephan KE, Kötter R (2002) The anatomical basis of functional localization in the cortex. Nat Rev Neurosci 3:606-616. Medline

Posner MI (2012) Imaging attention networks. Neuroimage 61:450-456. CrossRef Medline

Pujol J, Soriano-Mas C, Ortiz H, Sebastián-Gallés N, Losilla JM, Deus J (2006) Myelination of language-related areas in the developing brain. Neurology 66:339-343. CrossRef Medline

Sadeghi N, Prastawa M, Fletcher PT, Wolff J, Gilmore JH, Gerig G (2013) Regional characterization of longitudinal DT-MRI to study white matter maturation of the early developing brain. Neuroimage 68:236-247. CrossRef Medline

Shapleske J, Rossell SL, Woodruff PW, David AS (1999) The planum temporale: a systematic, quantitative review of its structural, functional and clinical significance. Brain Res Rev 29:26-49. CrossRef Medline

Shaw P, Greenstein D, Lerch J, Clasen L, Lenroot R, Gogtay N, Evans A, Rapoport J, Giedd J (2006) Intellectual ability and cortical development in children and adolescents. Nature 440:676-679. CrossRef Medline

Thompson PM, Cannon TD, Narr KL, van Erp T, Poutanen VP, Huttunen M, Lönnqvist J, Standertskjöld-Nordenstam C, Kaprio J, Khaledy M, Dail R, Zoumalan CI, Toga AW (2001) Genetic influences on brain structure. Nat Neurosci 4:1253-1258. CrossRef Medline

Toga AW, Thompson PM (2003) Mapping brain asymmetry. Nat Rev Neurosci 4:37-48. CrossRef Medline

Wahl M, Marzinzik F, Friederici AD, Hahne A, Kupsch A, Schneider GH, Saddy D, Curio G, Klostermann F (2008) The human thalamus processes syntactic and semantic language violations. Neuron 59:695-707. CrossRef Medline

Whittall KP, Mackay AL, Graeb DA, Nugent RA, Li DK, Paty DW (1997) In vivo measurement of T2 distributions and water contents in normal human brain. Magn Reson Med 37:34-43. CrossRef Medline 